\title{
Higher risk of complications in odynophagia- associated dysphagia in amyotrophic lateral sclerosis
}

\author{
Disfagia associada à odinofagia na esclerose lateral amiotrófica pode sugerir maior risco \\ para complicações pulmonares e nutricionais
}

Karen Fontes Luchesi ${ }^{1}$, Satoshi Kitamura ${ }^{2}$, Lucia Figueiredo Mourão ${ }^{3}$

\begin{abstract}
Objective: This investigation aimed to identify associated factors with dysphagia severity in amyotrophic lateral sclerosis (ALS). Method: We performed a cross-sectional study of 49 patients with ALS. All patients underwent fiberoptic endoscopy evaluation of swallowing and answered a verbal questionnaire about swallowing complaints. The patients were divided into groups according to dysphagia severity. Results: Among the factors analyzed, only odynophagia was associated with moderate or severe dysphagia. Conclusion: Odynophagia was associated with moderate and severe dysphagia in ALS and suggests a high risk of pulmonary and nutritional complications.
\end{abstract}

Keywords: amyotrophic lateral sclerosis, dysphagia, neurodegenerative disorders, malnutrition, pneumonia, pain.

\section{RESUMO}

Objetivo: Identificar fatores associados com a gravidade da disfagia na esclerose lateral amiotrófica (ELA). Método: Estudo transversal incluindo 49 sujeitos com esclerose lateral amiotrófica. Todos foram submetidos à videoendoscopia da deglutição e responderam a um questionário sobre queixas de deglutição. Foram divididos em grupos de acordo com a gravidade da disfagia. Resultados: Dentre os fatores estudados, apenas a odinofagia foi significantemente associada à disfagia moderada ou grave. Conclusão: A odinofagia foi associada à disfagia moderada ou grave na ELA e sua presença sugere maior risco para complicações pulmonares e nutricionais.

Palavras-chave: esclerose lateral amiotrófica, disfagia, doenças neurodegenerativas, desnutrição, pneumonia, dor.

In patients with neurodegenerative disease one of the major causes of death is aspiration pneumonia ${ }^{1-3}$. The treatment of dysphagia in such patients can prolong life expectancy and improve quality of life. Among the motor neuron diseases, amyotrophic lateral sclerosis (ALS) is the most common $^{1}$. It is a neurodegenerative disease with a life expectancy of 3 to 5 years after symptom onset ${ }^{4,5}$. Patients with ALS who have bulbar involvement at disease onset and develop symptoms such as dysphagia and dysarthria first have an even lower life expectancy ${ }^{6}$.

ALS is characterized by motor paralysis owing to degeneration of motor neurons in the primary motor cortex, brainstem and spinal cord, without impairment of sensitivity. Dysphagia in ALS is progressive, and begins with weakness and spasticity of muscles innervated by the trigeminal, facial, hypoglossal, glossopharyngeal, and vagus nerves ${ }^{2}$.

The identification of dysphagia severity and associated factors that lead to nutritional and pulmonary complications can be a form of preventitive care. Even today, many of these patients do not receive the desired attention and treatment for dysphagia, and swallowing dysfunction can lead to death.

Non-motor symptoms, including pain, are frequently not reported in ALS; however, studies indicate that 50 to $70 \%$ of ALS patients experience bodily pains ${ }^{7,8}$. The most often reported locations are the upper and lower extremities, shoulders, and hips ${ }^{9}$. Odynophagia is perceived as pain evoked during swallowing ${ }^{10}$. Depending on the impairment of the swallowing mechanism, dysphagia and odynophagia

${ }^{1}$ Speech-Language Therapist. Doutora em Saúde Coletiva. Universidade Estadual de Campinas, Campinas SP, Brazil;

${ }^{2}$ Physician. Doutor em Ciências Médicas. Professor da Faculdade de Ciências Médicas, Universidade Estadual de Campinas, Campinas SP, Brazil; ${ }^{3}$ Speech-Language Therapist. Doutora em Neurologia. Professora da Faculdade de Ciências Médicas, Universidade Estadual de Campinas, Campinas SP, Correspondence: Karen Fontes Luchesi, Centro de Estudos e Pesquisas em Reabilitação, Faculdade de Ciências Médicas, Universidade Estadual de Campinas; Av. Tessália Vieira de Camargo, 126 - Cidade Universitária; 13083-887 Campinas SP - Brasil; E-mail: karenluchesi@yahoo.com.br.

Conflict of interest: There is no conflict of interest to declare.

Received 27 April 2013; Received in final form 15 November 2013; Accepted 22 November 2013. 
can be felt simultaneously ${ }^{11}$. The physiopathology of pain in ALS patients is not clear. It is speculated that odynophagia is somehow connected with the activity of muscles in the larynx, pharynx, or even the esophagus.

There are no studies of odynophagia in ALS or its relationship with dysphagia severity. As an ALS symptom, pain is understudied and is not clearly understood by many doctors and researchers. Despite this, it is not infrequent to find patients in daily neurological practice who complain of painful swallowing, albeit to different degrees, at some point in their disease course. The purpose of the present study was to identify factors associated with dysphagia severity in patients with ALS.

\section{METHOD}

\section{Patient Selection}

We performed a cross-sectional study in 49 patients previously diagnosed with ALS (according to the El Escorial criteria) $)^{12}$ in a large Brazilian university hospital. All patients answered a verbal questionnaire about their swallowing complaints administered by a speech-language therapist, and underwent fiberoptic endoscopy evaluation of swallowing (FEES).

The study included patients with ALS who had one or more complaints of swallowing and who were being treated with riluzole. We excluded patients who could not undergo FEES or who had frontotemporal involvement or another disorder affecting swallowing. This study was approved by the research and ethics committee of the Faculty of Medical Sciences, University of Campinas, Brazil, under the number 796/2005.

\section{Procedures}

At the clinical evaluation, the patients' current age, age at symptom onset, and complaints regarding oral and pharyngeal swallowing phases were noted.

Patients answered the verbal questionnaire with "yes" or "no" with regard to oral complaints (labial food escape, chewing difficulty, palatal food residues, difficulty ejecting the bolus, food residue in the oral cavity, labial escape of liquid or saliva, and difficulty in swallowing saliva), pharyngeal complaints (nasal reflux of food or liquid, coughing, gagging, throat clearing during or after feeding, sensation of food stasis, painful swallowing [odynophagia], and swallowing difficulties and swallowing delays), and chest pain.

Three types of food were offered during the examination: 1) lemon juice colored with green dye; 2) nectar, honey, and pudding consistencies, all colored with green dye (these fluids were obtained with the addition of 2,3 , and 4 teaspoons of a thickener [Thicken-easy ${ }^{\mathbb{B}}$ ] to $100 \mathrm{~mL}$ of water, respectively, offered in two different quantities, 3 and $7 \mathrm{~mL}$ ); and 3) a solid consistency represented by a cornstarch biscuit.

The food was given to patients in the following sequence: liquid and nectar $(3 \mathrm{~mL}, 3 \mathrm{~mL}, 7 \mathrm{~mL}$, and $7 \mathrm{~mL})$; honey (3mL, $3 \mathrm{~mL}, 7 \mathrm{~mL}$, and $7 \mathrm{~mL}$ ); pudding (2 tablespoons); and solid ( $1 / 2$ cornstarch biscuit). The liquid food was administered in $20 \mathrm{~mL}$ syringes, with the sample introduced into the patient's oral cavity. As difficulties in swallowing were observed, protective maneuvers of the airways and/or changes in head posture were performed to safely assist oral feeding. FEES studies were carried out by an otorhinolaryngologist, and the food was offered by a speechlanguage therapist.

The FEES results were judged by two speech therapists and one otorhinolaryngologist. They were categorized according to the classification of Macedo Filho et al. ${ }^{13}$ : level 0) normal swallowing: normal oral containment, presence of reflexes, absence of salivary or food stasis, fewer than three propulsion attempts to clear the bolus; level 1) mild dysphagia: limited stasis after swallowing, fewer than three propulsion attempts to clear the bolus, no nasal regurgitation or laryngeal penetration; level 2) moderate dysphagia: moderate salivary stasis, greater stasis after swallowing, more than three attempts to clear the bolus, nasal regurgitation, reduced laryngeal sensitivity with penetration, but without laryngotracheal aspiration; and level 3) severe dysphagia: large salivary stasis, marked impairment in the amount of residue after swallowing, weak or absent propulsion, nasal regurgitation, and laryngotracheal aspiration.

\section{Data Analysis}

The patients were divided into two groups according to FEES-classifed dysphagia severity: group 1) patients with normal swallowing or mild dysphagia, and group 2) patients with moderate or severe dysphagia. Descriptive analysis was performed to determine the frequencies of categorical variables, and mean and standard deviation were calculated for numeric variables.

To identify factors associated with moderate or severe dysphagia, Cox's regression was performed to analyze single to multiple variables, using a stepwise process. The multiple variable analyses were used to exclude those variables that did not apply and to obtain a factor more closely associated with dysphagia severity.

Dysphagia severity (group 1 or 2) was considered the dependent variable in Cox's regression. The independent variables tested were: age at assessment; age at symptom onset; disease duration (time estimated between age at symptom onset and age at assessment); gender; numbers and types of swallowing complaints during the oral and pharyngeal phases, and complaint of chest pain. 
Statistical analyses were performed using Statistical Package for the Social Sciences (SPSS) version 13.0 for Windows (SPSS Inc., Chicago, IL, USA), and p-values $<0.05$ were considered significant.

\section{RESULTS}

Based on the classification of the dysphagia severity, patients were distributed into groups: 25 in group 1 (3 [6.1\%] had normal swallowing and 22 [44.9\%] had mild dysphagia) and 24 in group 2 (20 [40.8\%] had moderate dysphagia and 4 [8.1\%] had severe dysphagia). Table 1 shows the descriptive analysis for patient characterization. Tables 2 and 3 show the frequencies of swallowing complaints in the oral and pharyngeal phases, respectively.

The number of swallowing complaints for the oral and pharyngeal phases, the reference of difficulty ejecting the bolus, and odynophagia were identified as factors associated with moderate or severe dysphagia in single variable analysis (Table 4).

Only odynophagia remained as an associated factor of moderate or severe dysphagia in the multiple variable analysis (risk: 11.96; confidence interval: 1.60 to 89.36, $\mathrm{p}=0.01$ ). Odynophagia was noted in $31(63.2 \%)$ patients; $9(36 \%)$ and $22(91.6 \%)$ in groups 1 and 2, respectively. Odynophagia was assigned as generally painful swallowing. We did not specifically identify where pain was felt or if it was in the oral or pharyngeal phase because the data collection was dichotomic. The patient simply answered "yes" or "no" when they were asked about the "presence of painful swallowing."

Chest pain, which can suggest lung or esophagus involvement, was reported by $26(78.7 \%)$ patients: $9(36 \%)$ in group 1 and 17 (70.8\%) in group 2. Notably, 20 of the 26 patients reported simultaneous chest pain and painful swallowing. We did not find a significant association between chest pain and dysphagia severity $(\mathrm{p}=0.08)$, but we did find a relationship between chest pain and painful swallowing ( $\mathrm{p}=0.03)$.

\section{DISCUSSION}

We found that almost all patients had experienced some level of dysphagia at the time of evaluation. During ALS progression, generally all patients will suffer from dysphagia at some time during the disease course. It is a rapidly evolving disease, and we found that the majority of the patients were diagnosed with mild or moderate dysphagia within 2 years of ALS duration. Studies conducted in the United States and Italy reported similar prevalences of mild and moderate dysphagia in ALS patients ${ }^{1,14}$.

Due to the preservation of oropharyngeal sensitivity in ALS, patients perceive each of their dysphagia symptoms and experienced increased symptom frequency during feeding. The analysis showed that a greater number of swallowing complaints was associated with higher risk of moderate or severe dysphagia.

There are controversies regarding pain in ALS. The multiple variable analyses results demonstrated that odynophagia (painful swallowing) was associated with dysphagia severity in ALS. This association can be explained according to two hypotheses: weakness and muscular fatigue of pharyngeal and laryngeal muscles and/or esophagus hypertonicity and spasticity.

According to the literature, pain in ALS patients can be explained by spasticity, atrophy, stiffness, and reduced muscle tone. Pain can also increase mobility reduction, reduce motor coordination, and affect muscular function ${ }^{15}$. The muscle fatigue hypothesis considers that motor neuron degeneration leads to muscle denervation and produces muscle fatigue, weakness, and cramps. A weaker muscle requires an individual to work that muscle at increased intensities relative to its maximal capacity, inducing progressive fatigue and an increased sense of effort, which is sometimes described by the patient as pain. These alterations also cause abnormal stress on the ligaments, tendons, and joints that could result in trauma to the muscle and tendons, producing low levels of inflammation that eventually lead to the development of pain.

Table 1. Descriptive analysis of Brazilian patients with amyotrophic lateral sclerosis classified according to dysphagia severity $(n=49)$.

\begin{tabular}{|c|c|c|}
\hline & $\begin{array}{l}\text { Group 1: Normal swallowing and mild dysphagia } \\
\qquad(n=25) \\
\text { Mean }\left( \pm S D^{a}\right)\end{array}$ & $\begin{array}{l}\text { Group 2: Moderate and severe dysphagia } \\
\qquad(n=24) \\
\text { Mean }\left( \pm S D^{a}\right)\end{array}$ \\
\hline Gender (male/female) & $13 / 12$ & $14 / 10$ \\
\hline Age at symptoms' onset (years) & $52.1( \pm 10.5)$ & $52.7( \pm 9.6)$ \\
\hline Age at first assessment (years) & $54.4( \pm 11)$ & $55( \pm 9.2)$ \\
\hline Disease duration (years) & $2.29( \pm 1.8)$ & $2.2( \pm 1.5)$ \\
\hline Swallowing complaints ( $n$ ) & $5.6( \pm 4)$ & $10( \pm 2)$ \\
\hline Swallowing complaints in oral phase (n) & $2.6( \pm 2.5)$ & $4.8( \pm 2)$ \\
\hline Swallowing complaints in pharyngeal phase (n) & $3( \pm 2)$ & $5( \pm 3)$ \\
\hline
\end{tabular}

a Standard deviation (SD) 
Table 2. Frequency of swallowing complaints in the oral phase observed by Brazilian patients with amyotrophic lateral sclerosis, classified according to dysphagia severity $(n=49)$.

\begin{tabular}{lcc} 
Complaints & $\begin{array}{c}\text { Group 1: Normal swallowing and mild dysphagia } \\
(\mathrm{n}=25) \\
\mathrm{n}(\%)\end{array}$ & $\begin{array}{c}\text { Group 2: Moderate and severe dysphagia } \\
(\mathrm{n}=24) \\
\mathrm{n}(\%)\end{array}$ \\
\hline Labial food escape & $10(40.0)$ & $16(66.6)$ \\
Chewing difficulty & $13(52.0)$ & $17(70.8)$ \\
Palatal food residues & $12(48.0)$ & $13(54.1)$ \\
Difficulty in ejecting the bolus & $10(40.0)$ & $20(83.3)$ \\
Food residue in the oral cavity & $12(48.0)$ & $17(70.8)$ \\
Labial escape of liquid or saliva & $13(52.0)$ & $17(70.8)$ \\
Difficulty in swallowing saliva & $4(16.0)$ & $4(16.6)$
\end{tabular}

According to Handy et al. ${ }^{16}$, the progressive degeneration of electrical and mechanical properties of the muscles reduces strength and coordination and stresses the ligaments, tendons, and joints. Such changes occur repeatedly and constantly, resulting in minor inflammation and consequent pain. Bettschneider et al. ${ }^{17}$ reported that the spasms, contractions, and abnormal stress on the system imposed by skeletal muscle weakness may also cause pain due to the immobilization of the articular blocks.

The combination of denervation and spasticity occurring in the pharynx, larynx, and esophagus muscles of ALS patients produces altered contractions. Deglutition could stress their tendons and points of insertion, producing micro bleeds and inflammation that result in pain during swallowing. It is important to consider that is very difficult to separate effort-fatigue, sometimes interpreted as pain, from real pain originated in muscles, tendons, and their points of insertion in clinical settings.

The second hypothesis is related to esophagus hypertonicity and spasticity. ALS patients frequently suffer spasticity of the cricopharyngeal muscle (i.e., upper esophageal sphincter). The lack of coordination between laryngeal elevator muscles and the cricopharyngeal sphincter is strongly related to dysphagia severity, even though chest pain (which would represent indirect esophageal impairment) and dysphagia severity were not directly related in the present study.
Laryngeal elevator and cricopharyngeal muscle incoordination can cause pain owing to spasticity, rigidity, and bronchoaspiration. The explanation for aspiration of food or liquid is the shorter opening time and premature closure of the upper esophageal sphincter that occurs before the larynx descends from the upward position. This causes stasis of the bolus in pharyngeal spaces, and then, after the larynx has descended from the upper location, the bolus escapes into the airway, resulting in subglottal aspiration ${ }^{18}$. This hypothesis is supported by the association between odynophagia and chest pain.

In the present study, the pain reported by the patients was associated with more severe stages of dysphagia. According to Simons ${ }^{19}$, as ALS progresses and mobility decreases due to weakness and spasticity, ALS patients experience increased pain frequency. Pain can be felt in the oral, pharyngeal, and/or esophageal phases of swallowing.

This study has limitations in that we did not specifically assess the type, intensity, localization, and moment of painful swallowing. In addition, the confidence intervals were quite large. Although odynophagia was identified as a factor associated with moderate or severe dysphagia, how its occurrence may increase the risk of moderate or severe dysphagia could not be generalized owing to the weak statistical evidence.

Coughing is the major risk factor for laryngotracheal aspiration in the literature ${ }^{20}$. However, in patients with ALS coughing is usually weak or absent. The existence of

Table 3. Frequency of swallowing complaints in the pharyngeal phase observed by Brazilian patients with amyotrophic lateral sclerosis, classified according to dysphagia severity $(n=49)$.

\begin{tabular}{lcc} 
Complaints & $\begin{array}{c}\text { Group 1: Normal swallowing and mild dysphagia } \\
(\mathrm{n}=25)\end{array}$ & $\begin{array}{c}\text { Group 2: Moderate and severe dysphagia } \\
(\mathrm{n}=24) \\
\mathrm{n}(\%)\end{array}$ \\
\hline Nasal reflux & $5(20.0)$ & $7(29.1)$ \\
Coughing & $4(16.0)$ & $4(16.6)$ \\
Gagging & $16(64.0)$ & $22(91.6)$ \\
Throat clearing & $14(56.0)$ & $16(66.6)$ \\
Sensation of food stasis & $19(76.0)$ & $16(66.6)$ \\
Painful swallowing & $9(36.0)$ & $22(91.6)$ \\
(odynophagia) & $11(44.0)$ & $16(66.6)$ \\
Swallowing difficulties & $2(8.0)$ & $3(12.5)$ \\
Swallowing delays & & \\
\hline
\end{tabular}


Table 4. Associated factors of moderate or severe dysphagia identified by the single variable analysis of Cox's regression in a sample of 49 amyotrophic lateral sclerosis Brazilian patients.

\begin{tabular}{lccc}
\hline Variables & Prevalence & Confidence Interval & p-value \\
\hline Swallowing complaints in oral phase $(n)$ & 1.38 & $1.08-1.75$ & 0.009 \\
Swallowing complaints in pharyngeal phase $(n)$ & 1.20 & $1.01-1.43$ & 0.03 \\
Difficulty in ejecting the bolus (yes $\times$ no) & 3.16 & $1.08-9.26$ & 0.03 \\
Painful swallowing (odynophagia) (yes $\times$ no) & 6.38 & $1.50-27.16$ & 0.01 \\
\hline
\end{tabular}

odynophagia in ALS as a factor associated with dysphagia severity needs to be investigated further in additional longterm studies. Patients with ALS can reference symptoms of dysphagia, including the frequency of gagging or coughing (symptoms more commonly associated with severity), and maybe more specifically by the presence of painful swallowing. There is evidence that pain in ALS interferes with activities of daily life, as well as patients' social lives ${ }^{21}$. However, pain is one of the less studied, most underrated, and potentially least treated symptom of ALS. It is rarely discussed or reported by patients ${ }^{21}$. A recent Dutch study described pain as an unrecognized and untreated symptom of $\mathrm{ALS}^{22}$. The authors emphasized that efforts need to be made to identify it and treat it appropriately. Thus, more studies of odynophagia in ALS are needed to improve understanding of this symptom and identify effective management strategies.

In conclusion, the factor most consistently associated with dysphagia severity in ALS was odynophagia. This can be explained by two hypotheses: pharyngeal and laryngeal muscle weakness and fatigue, and/or or esophagus hypertonicity and spasticity. The presence of odynophagia in ALS patients is associated with a high risk of pulmonary and nutritional complications; therefore, it is important to ameliorate it to the greatest extent possible.

\section{References}

1. Fattori B, Grosso M, Bongioanni P, et al. Assessment of swallowing by oropharyngoesophageal scintilography in patients with amyotrophic lateral sclerosis. Dysphagia 2006;21:280-286

2. Janzen VD, Hae R, Hudson AJ. Otolaryngologic manifestations of amyotrophic lateral sclerosis. J Otolaryngol 1996;17:41-42.

3. Hadjikoutis S, Wiles CM. Respiratory complications related to bulbar dysfunction in motor neuron disease. Acta Neurol Scand 2001;103:207-213.

4. Oliveira ASB, Pereira RDB. Amyotrophic lateral sclerosis (ALS) three letters that change the people's life. Arq Neuropsiquiatr 2009;67:750-782

5. O’toole O, Traynor BJ, Brennan P, et al. Epidemiology and clinical features of amyotrophic lateral sclerosis in Ireland between 1995 and 2004. J Neurol Neurosurg Psychiatry 2008;79:30-32.

6. Zoccolella S, Beghi E, Palagano G, et al. Analysis of survival and prognostic factors in amyotrophic lateral sclerosis: a population based study. J Neurol Neurosurg Psychiatry 2008;79:33-37.

7. Ganzini L, Johnston WS, Hoffman WF Correlates of suffering in amyotrophic lateral sclerosis. Neurology 1999;52:1434-1440.

8. Oliver D. The quality of care and symptom control-the effects on the terminal phase of ALS/MND. J Neurol Sci 1996;139(Suppl):S134-S136.

9. Chiò A, Canosa A, Gallo S, et al. Pain in amyotrophic lateral sclerosis: a population-based controlled study. Eur J Neurol 2012;19:551-555.

10. Wilson JD. Harrison's Principles of Internal Medicine. 12th edition. New York: McGraw-Hill; 1991:417.

11. Vaiman M, Eviatar E. Surface electromyography as a screening method for evaluation of dysphagia and odynophagia. Head Face Med 2009;5:1-11.

12. Brooks BR. El Escorial World Federation of Neurology criteria for the diagnosis of amyotrophic lateral sclerosis. Subcommittee on Motor
Neuron Diseases/Amyotrophic Lateral Sclerosis of the World Federation of Neurology Research Group on Neuromuscular Diseases and the El Escorial "Clinical limits of amyotrophic lateral sclerosis" workshop contributors. J Neurol Sci 1994;124(Suppl):S96-S107.

13. Macedo Filho ED, Gomes GF, Furkim AM. Manual de cuidados do paciente com disfagia. São Paulo: Lovise, 2000.

14. Pontes RT, Orsini M, Freitas MRG, Antonioli RS, Nascimento OFM Alterações da fonação e deglutição na esclerose lateral amiotrófica: revisão de literatura. Rev Neurocienc 2010;18:69-73.

15. Thomas CK, Zijdewind I. Fatigue of muscles weakened by death of motoneurons. Muscle Nerve 2006;33:21-41.

16. Handy CR, Krudy C, Boulis N, Federici T. Pain in amyotrophic lateral sclerosis: a neglected aspect of disease. Neurol Res Int 2011;1:1-8.

17. Brettschneider J, Kurent J, Ludolph A, Mitchell JD. Drug therapy for pain in amyotrophic lateral sclerosis or motor neuron disease. Cochrane Database Syst Rev 2008;3:CD005226.

18. Ertekin C, Aydogdu I, Yüceyar N, Kiylioglu N, Tarlaci S, Uludag B Pathophysiological mechanisms of oropharyngeal dysphagia in amyotrophic lateral sclerosis. Brain 2000;123:125-140.

19. Simmons Z. Management strategies for patients with amyotrophic lateral sclerosis from diagnosis through death. Neurologist 2005;11:257-270.

20. Garon BR, Engle M, Ormiston C. Reliability of the 3-oz water swallow test utilizing cough reflex as sole indicator of aspiration. J Neurol Rehab 1995;9:139-143.

21. Pagnini F, Lunetta C, Banfi P, et al. Pain in amyotrophic lateral sclerosis: a psychological perspective. Neurol Sci 2012;33:1193-1196.

22. Maessen M, Veldink JH, van den Berg LH, Schouten HJ, van der Wa Onwuteaka-Philipsen BD. Requests for euthanasia: origin of suffering in ALS, heart failure, and cancer patients. J Neurol 2010;257:1192-1198. 